\title{
¿GARANTIZA O FONDO DE RESERVA A SUSTENTABILIDADE DO SISTEMA PÚBLICO DE PENSIÓNS?
}

Mercedes Mareque Álvarez-Santullano. Profesora Axudante Doutora da Universidade de Vigo. Facultade de Ciencias Empresariais e Turismo. Campus Universitario, s/ n - 32004 Ourense.. E-mail: chedesmareque@uvigo.es Francisco López-Corrales. Profesor Titular da Universidade de Vigo. Facultade de Ciencias Sociais e da Comunicación. Campus A Xunqueira, s/n. 36005 Pontevedra.. Email: corrales@uvigo.es

Grupo de investigación: COAFIN pertencente a ECOBAS, código AGRUP2015/ 08.

Resumo: Dende hai décadas fálase da crise financeira que sofren os sistemas de pensións, o cal derivou na necesidade de instaurar mecanismos de estabilización e reformas co obxectivo de solucionar eses desequilibrios. O Fondo de Reserva é un dos mecanismos utilizados para corrixir as situacións de desequilibrio actuarial do sistema de pensións, actuando perante as crises demográficas e económicas. Este estudo ten como obxectivo a análise da evolución e situación actual do Fondo de Reserva da Seguridade Social en España, e do seu papel na sustentabilidade do sistema público de pensións. O traballo permitiunos identificar oportunidades de mellora e establecer un conxunto de recomendacións que, de ser consideradas polos organismos oficiais poderían converter ao Fondo de Reserva nun elemento relevante na solvencia dos sistemas da Seguridade Social contribuíndo á súa sustentabilidade e aumentando a equidade entre as xeracións de pensionistas.

Palabras chave: Fondo de Reserva, Seguridade Social, reforma do sistema de pensións, sustentabilidade, transparencia.

Código JEL: H55 Seguridade social e pensións públicas

Does the Reserve Fund guarantee the sustainability of the state pension system?

Abstract: For decades there have been discussions over the financial crisis that pension systems are facing, which has led to the need of implementing stabilization mechanisms and reforms in order to address those imbalances. The Reserve Fund is one of the mechanisms used to correct the situations of actuarial imbalance of the pension system, acting upon the demographic and economic crisis. This study aims to analyze the evolution and current situation of the Social Security Reserve Fund in Spain, and its role in the sustainability of the state pension system. Our research has allowed us to identify opportunities for improvement and establish a set of recommendations that, if taken into account by the government agencies involved, could turn the Reserve Fund into a relevant element in the solvency of the Social Security systems, contributing to its sustainability and increasing equity among the generations of pensioners.

Key words: Reserve fund, Social Security, pensions fund reform, sustainability, transparency.

\section{INTRODUCIÓN}

A viabilidade futura do sistema da Seguridade Social é un tema de interese colectivo, que esperta a atención e o debate de investigadores e de distintos grupos de interese ( directivos, empresarios, traballadores,....). Dende hai décadas fálase da crise financeira da Seguridade Social en España, acentuada nos últimos anos pola situación económica do país. O cuestionamiento da sustentabilidade da Seguridade Social explícase fundamentalmente polos cambios demográficos que se veñen producindo dende hai anos, no só en España, senón en moitos países desenvolvidos. As proxeccións realizadas pola Comisión Europea indican que o avellentamento poboacional supón un gran desafío para a sustentabilidade das finanzas públicas, dado o substancial impacto fiscal que se proxecta en case todos os países da UE (European Commission, 2012). 
Isto xerou a necesidade de instaurar mecanismos de estabilización e reformas nos sistemas públicos de pensións. Os Fondos de Reserva son un dos mecanismos utilizados para corrixir as situacións de desequilibrio actuarial dos sistemas de pensións, actuando perante crises demográficas e económicas. Case a metade dos países da OECD constituíron Fondos de Reserva para axudar a pagar as súas pensións públicas no futuro (OECD, 2012). Existe un amplo debate social sobre a necesidade de reformar os sistemas de pensións, de cara a que sexan máis eficientes e financeiramente sostibles, existindo un consenso xeneralizado de que estas reformas se deben levar a cabo nos sistemas de pensións nos distintos países baseándose en diversos instrumentos. Así, dunha banda, fálase das reformas paramétricas e doutra, das reformas estruturais.

Nos ano 2010 o Libro Verde das pensións (Comisión Europea, 2010) da inicio a un debate público sobre a reforma do sistema de pensións, sinalando que a reforma debe ir encamiñada cara o cumprimiento de tres grandes obxectivos: a adecuación, a modernización e a sustentabilidade do sistema. No caso de España este debate iníciase a mediados da segunda metade da década dos anos noventa (ver Herce e Pérez-Díaz, 1995; Ministerio de Traballo e Seguridade Social, 1995; Herce et al., 1996; Piñera e Weinstein, 1996; Barea et al., 1997), o cal conclúe coa aprobación no Congreso dos Deputados en abril de 1995 do coñecido como "Pacto de Toledo", se ben continúa na actualidade, pois no ano 2011 apróbase a reforma do sistema de pensións máis importante das últimas décadas, mediante a aprobación da Lei $27 / 2011$, sobre actualización, adecuación e modernización do sistema da Seguridade Social, incluíndo como principais medidas da reforma o retraso da idade de xubilación, o aumento do período de cotización necesario para recibir unha porcentaxe da base reguladora e a ampliación do período de cómputo para o cálculo da pensión. Ademais, introdúcese no sistema a figura do factor de sustentabilidade e do índice de revalorización, co obxectivo de garantir a súa sustentabilidade e para manter a proporcionalidade entre as contribucións e as prestacións esperadas.

Neste senso, este traballo pretende contribuír a ampliar e extender o debate público sobre a sustentabilidade dos sistemas de pensións, identificando oportunidades de mellora e establecendo un conxunto de recomendacións que, de ser consideradas polos organismos oficiais, poderían converter o Fondo de Reserva nun elemento relevante na solvencia dos sistemas de Seguridade Social contribuíndo á súa sustentabilidade e aumentando a equidade entre as xeracións de pensionistas.

O traballo está estruturado da seguinte maneira, despois desta introdución facemos referencia á evolución, á xestión e investimento do Fondo de reserva, seguidamente comentamos o papel do Fondo de Reserva na solvencia do rexime de pensións, facendo fincapé nas súas reformas máis recentes. Finalizamos o traballo coas conclusións máis relevantes e cunha serie de recomendacións que, de ser instauradas, poderían converter o Fondo de Reserva nun elemento chave na sustentabilidade do sistema de pensións públicas.

2. Evolución dO Fondo de Reserva

A lexislación española establece que os activos nos que se materializara o Fondo de Reserva só se poderán destinar para o financiamento das pensións de carácter contributivo e dos gastos asociados á súa xestión, cun máximo anual do $3 \%$ da suma de ambos conceptos, e debendo ter a autorización previa do Consello de Ministros, a proposta conxunta dos Ministros de Traballo e Asuntos Sociais, Facenda e Economía. 
A disposición dos devanditos activos só se contempla na Lei baixo unha situación de déficit estrutural no financeiro do sistema da Seguridade Social, nas operacións de natureza contributiva e demais gastos asociados. En xeral, enténdese por situación estrutural de déficit as operacións non financeiras, cando as previsións de liquidación do excedente orzamentario das Entidades Xestoras e Servizos Comúns, calculadas a efectos do Fondo de Reserva, máis o exceso de excedentes das Mutuas, reflictan un resultado negativo durante tres semestres consecutivos, constituíndo estes un exercicio tamén negativo.

A crise económica xerou nos últimos anos a caída dos ingresos do sistema de pensións, que unida ao incremento dos gastos, provocou o peche dos exercicios 2010 e 2011 en déficit (Ministerio da Presidencia, 2012) ${ }^{1}$. A consecuencia disto, establécese un rexime excepcional de disposición de activos do Fondo de Reserva, de forma que durante os exercicios 2012, 2013 e 2014 non aplicou o mencionado límite de disposición do Fondo do 3\% fixado na Lei. Así, en 2012 a Seguridade Social dispuxo por primeira vez dos recursos do Fondo de Reserva, para facer fronte á insuficiencia de liquidez.

Con respecto a isto, autores como Barea (2012) consideran que se acode moi cedo ao Fondo de Reserva, afirmando que esta decisión "pon de manifesto a mala previsión do gasto en prestacións da Seguridade Social". Zubiri $(2013,2003)$ opina que o Fondo pódese utilizar conxunturalmente, malia que calquera disposición antes de 2030 debería ser reposta, limitándose o importe anual das disposicións ao $2 \%$ do PIB.

A Táboa 1 amosa as dotacións e disposicións efectuadas no Fondo de Reserva en España dende que se constituiu no ano 2000, así como os rendementos obtidos que, de acordo ao establecido por lei, intégranse de maneira automática nas dotacións do Fondo.

TÁBOA 1.- Evolución do Fondo de Reserva (importes en millóns de euros)

${ }^{1}$ O excedente calculado a efectos do Fondo de Reserva pasou de 10.357,05 millóns de euros en 2008 (Ministerio da Presidencia, 2010), a un déficit de 11.818,01 millóns de euros en 2012, segundo cálculo provisional da Intervención Xeral da Seguridade Social a 21 de novembro de 2012 (Goberno de España, 2013). 


\begin{tabular}{|c|c|c|c|c|c|c|}
\hline \multirow[b]{2}{*}{$A N \bar{O}$} & \multicolumn{2}{|c|}{ DOTACIONES } & \multirow[b]{2}{*}{ DISPOSICIONES } & \multirow[b]{2}{*}{$\begin{array}{c}\text { RENDIMIENTOS } \\
\text { NETOS }\end{array}$} & \multirow[b]{2}{*}{$\begin{array}{c}\text { FONDO } \\
\text { RESERVA A } \\
\text { CIERRE DE } \\
\text { EJERCICIO }\end{array}$} & \multirow[b]{2}{*}{$\begin{array}{c}\text { FONDO } \\
\text { RESERVA } \\
\text { COMO \% } \\
\text { DEL PIB }\end{array}$} \\
\hline & $\begin{array}{l}\text { ACUERDO } \\
\text { CONSEIODE } \\
\text { MINISTROS }\end{array}$ & $\begin{array}{l}\text { EXCEDENTE } \\
\text { SMUTUAS }\end{array}$ & & & & \\
\hline 2000 & 601 & - & - & 3 & 604 & - \\
\hline 2001 & 1.803 & - & - & 26 & 2.433 & - \\
\hline 2002 & 3.575 & - & - & 161 & 6.169 & - \\
\hline 2003 & 5.494 & - & - & 362 & 12.025 & - \\
\hline 2004 & 6.700 & 20 & - & 585 & 19.330 & - \\
\hline 2005 & 7.000 & 5 & - & 850 & 27.185 & $3,25 \%$ \\
\hline 2006 & 7.500 & 42 & - & 1.152 & 35.879 & $3,96 \%$ \\
\hline 2007 & 8.300 & 110 & - & 1.427 & 45.716 & $4,66 \%$ \\
\hline 2008 & 9.400 & 120 & $=$ & 1.987 & 57.223 & $5,45 \%$ \\
\hline 2009 & - & 80 & - & 2.719 & 60.022 & $5,51 \%$ \\
\hline 2010 & 1.740 & 69 & - & 2.544 & 64.375 & $6,11 \%$ \\
\hline 2011 & - & 223 & - & 2.217 & 66.815 & $6,22 \%$ \\
\hline 2012 & - & 226 & -7.003 & 2.970 & 63.008 & $5,93 \%$ \\
\hline 2013 & - & 197 & -11.648 & 2.187 & 53.744 & $5,25 \%$ \\
\hline 2014 & - & 279 & -15.300 & 2.911 & 41.634 & $3,93 \%$ \\
\hline 2015 & - & 103 & -13.250 & 3.994 & 32.481 & $3,00 \%$ \\
\hline $\begin{array}{c}\text { TOMAL } \\
\text { ACUMULADO }\end{array}$ & 52113 & 1.474 & -47.201 & 26.095 & & \\
\hline
\end{tabular}

FONTE: Elaboración propia a partir de MEYSS $(2012,2013,2014,2015)$

Segundo o último informe oficial anual das Cortes Xerais do ano 2015 (MEYSS, 2015), o Fondo de Reserva a 31 de decembro deste ano situouse en 32.481 millóns de euros, cifra que representa o 3\% do PIB do ano 2015. O 65\% do devandito importe provén das aportacións acordadas polo Consello de Ministros con cargo aos excedentes orzamentarios das entidades xestoras, namentres que as dotacións provenientes das mutuas apenas representan o $1,8 \%$ do total.

As aportacións acordadas tiveron unha evolución crecente ata o exercicio 2008, a partir do cal o Consello de Ministros só decidiu unha dotación ao Fondo no ano 2010 por un importe moi inferior ás anteriores aportacións (menos do 20\% da última). Así, nos últimos cinco exercicios só se dotou con cargo aos excedentes das entidades xestoras no ano 2010. No acordo para a dotación de 2010 indicábase que a mesma se efectuaba con cargo aos excedentes do exercicio 2008, calculados en 10.357 millóns de euros, polo que a cantidade destinada ao Fondo de Reserva foi só o 16,8\% deses excedentes.

A lexislación española non establece a obriga de efectuar dotacións ao Fondo de Reserva con cargo aos excedentes das entidades xestoras, só se deben destinar ao mesmo de forma maioritaria, sempre que as posibilidades económicas e a situación financeira do sistema de Seguridade Social o permitan. Nos informes oficiais sobre o Fondo de Reserva, e nos acordos dos Consellos de Ministros, non se indican nin os importes dos excedentes orzamentarios a efectos do Fondo de Reserva, nin as razóns para a dotación das cantidades acordadas polo Consello de Ministros. É máis, os devanditos excedentes non son publicados de forma regular, nin é posible o seu cálculo a partir da información pública; só os excedentes dalgúns anos foron indicados nos Consellos de Ministros. A falta de dotación ao Fondo en 2009 parece deberse á decisión de contar con recursos para 
instituír medidas de axuda a empresas e traballadores como os aprazamentos de pago das débedas contraídas coa Seguridade Social (UGT-CEC, 2010:9).

Como se aprecia na Táboa 1, con respecto ás disposicións, as últimas foron realizadas no ano 2015, concretamente no mes de xullo e decembro. En ámbolos meses a Seguridade Social ten importantes necesidades de liquidez, xa que ademais ten que desembolsar a nómina habitual aos pensionistas, debendo facer fronte ao pago das pagas extra. $\mathrm{O}$ Ministerio de Emprego e Seguridade Social durante o ano 2015 dispuxo un total de 13.250 millóns de euros, o que sitúa ao Fondo en 32.481 millóns de euros, e supón un 3\% do PIB (a valor de mercado 35.035 millóns de euros, o 3,24\% del PIB), menos da metade dos 66.815 millóns de euros que acumulaba o Fondo a finais del ano 2011. Este importe disposto en 2015, 13.250 millóns de euros, representa o 31,82\% do total acumulado no Fondo de Reserva no peche do ano anterior (MEYSS, 2015).

A crise económica que afecta a España supuxo durante o exercicio 2012 un importante déficit do sistema da Seguridade Social, daí que o goberno decide neste ano dispoñer do Fondo de Reserva para facer fronte ao pago das pensións. Ao ser o límite de disposición do Fondo permitido pola lexislación do $3 \%$, foi necesaria a eliminación de tal restrición mediante a aprobación do RDL 28/2012, de Medidas de consolidación e garantía do sistema da Seguridade Social, onde se establece o rexime excepcional de disposición dos activos do Fondo de Reserva para os exercicios 2012, 2013 e 2014, aínda que como acabamos de comentar seguiuse dispoñendo do Fondo durante o ano 2015.

As diferentes decisións de dotación e disposición do Fondo de Reserva non parecen que tomara en consideración o efecto das mesmas sobre a solvencia e sustentabilidade do sistema de pensións, xa que non se fai referencia a este tipo de valoracións nin nos acordos dos Consellos de Ministros nin nos informes anuais sobre o Fondo de Reserva. De seguir este ritmo de disposición do Fondo sen realizar aportacións, en menos de 3 anos desaparecería.

\section{Xestión e investimento do fondo de reserva}

A Tesourería Xeral da Seguridade Social é o organismo encargado da xestión dos activos financeiros nos que se materializan as aportacións do Fondo de Reserva. Existen tres órganos propios de control e xestión do Fondo de Reserva: o Comité de Xestión, a Comisión Asesora de Investimentos e a Comisión de Seguimento. Cabe destacar a importante reordenación e reestruturación destes órganos que se prevía na frustrada proposta lexislativa de 2007, co fin de realizar unha diferenciación clara entre os órganos con competencias de decisión e supervisión daqueles que se encargarían basicamente da execución das políticas aplicables. contemplábase así a creación dun novo órgano, 0 Comité de Supervisión e Control (véxase López-Gandía, 2008:199-201).

O Comité de Xestión determina para cada ano os criterios de investimento a seguir, así como o calendario, o importe das disposicións de fondos e calquera aspecto necesario para unha xestión "eficiente, rendible, segura, diversificada e congruente cos prazos axeitados ás súas finalidades" (artigo 5 do RD 337/2004). A Lei Reguladora do Fondo de Reserva establece que os recursos do Fondo só poden estar investidos en títulos de Débeda Pública.

Os criterios aplicados sobre o investimento e xestión do Fondo de Reserva nos últimos exercicios non difiren substancialmente entre si. Existen variacións paulatinas en parámetros como a porcentaxe máxima dunha mesma referencia na carteira, que pasou do $12,5 \%$ en 2008 ao $15 \%$ en 2010 e, ao $16 \%$ a partir de 2012 ou, na porcentaxe que pode representar a carteira de investimentos en débeda española con respecto ao total da 
débeda do Tesouro de España en circulación, que pasou do 10\% en 2008 ao 11\% en 2010 e, ao $12 \%$ a partir de 2012 .

Os criterios do Fondo de Reserva establecen que se poderá investir tanto en Débeda Pública española como en estranxeira de máxima calidade crediticia (Alemaña, Francia e Países Baixos). Unha cuestión polémica relacionada cos investimentos do Fondo é que a parte da carteira investida en débeda estranxeira está moi lonxe do límite máximo (55\%) establecido nos criterios de investimento. A proporción de activos foráneos diminuiu drasticamente do $47 \%$ existente en 2007 ao 3\% en 2012 e 2013, pasando a ser o investimento en bonos estranxeiros totalmente nulo a partir do ano 2014 (MEYSS, 2008, 2013, 2014 e 2015). O elevado peso dos activos españois na carteira do Fondo foi moi cuestionado por non seguir os criterios de diversificación contemplados na propia lexislación do Fondo de Reserva.

A distribución actual da carteira pode responder ao criterio de rendibilidade (LópezSanguos e das Heras, 2012:165). Baixo outro punto de vista, hai opinións que consideran que é lóxico que os excedentes se invistan na nosa débeda e non sirvan para financiar a outros países (Meneu e Encinas, 2012:61). Isto contraponse co establecido nas Directivas para o investimento dos Fondos da Seguridade Social, establecidas pola Asociación Internacional da Seguridade Social (ISSA), que aínda que considera lexítimos os puntos de vista das autoridades financeiras nacionais, ao fixar a política e estratexia de investimento do Fondo de Reserva, non deberían ter dereito a ditar investimentos específicos (ISSA, 2004).

Botando un ollo cara o exterior, dos distintos tipos de activos nos cales invisten os diversos países: renda fixa, renda variable, terreos e construcións, efectivo e depósitos, investimentos en infraestruturas cotizadas, accións privadas e fondos de cobertura, outros (empréstitos, materias primas, ....), son os dous primeiros, renda fixa e variable os máis utilizados. Así, segundo datos da OCDE, no ano 2013, a carteira media dos Fondos de Reserva públicos amosan que o 55,3\% dos activos totais se investiron en renda fixa e efectivo, e o $30 \%$ en renda variable (accións cotizadas), e o 14,7\% en outros investimentos ou alternativas (OCDE, 2014).

Ademais, con algunhas excepcións, a meirande parte dos Fondos estranxeiros tratan de manter investimentos nos mercados foráneos a través tanto de renda fixa como de renda variable, incluso algúns, se ben son os menos, só invisten en alternativas estranxeiras. Por exemplo, Chile inviste o $100 \%$ da súa carteira no estranxeiro. Outros como Nova Zelanda, o AP1 e AP2 de Suecia e Canadá invisten máis do $60 \%$ do total dos seus activos nos mercados estranxeiros.

4. O fondo de reserva como mecanismo de sustentabilidade do sistema de pensións e as súas reformas recentes

O progresivo avellentamento da poboación, o incremento da esperanza de vida e a mortaldade, ademais dunha contorna económica cambiante que se caracteriza por baixos rendementos, crecemento baixo e taxas de interese baixas, está provocando que os sistemas de pensións teñan que se enfrontar a problemas de sustentabilidade financeira. Isto levou a que a meirande parte dos países decidiran acometer reformas nos seus sistemas de pensións co obxectivo de garantir a sustentabilidade financeira dos mesmos. A maioría dos países da OECD levaron a cabo dende os anos noventa reformas continuadas dos seus sistemas de pensións, e aproximadamente a metade deles realizaron fondas modificacións. Reformas moi activas desenvolveronse entre febreiro de 2012 e setembro de 2014. 
Países como Alemaña, Austria, Finlandia, Francia e Italia, xa presentaban a inicios dos anos noventa maiores gastos en pensións, por enriba do $10 \%$ do seu PIB, e este gasto continuou crecendo ao longo da década de 1990. Italia en 2005 chegou a ter un gasto de arredor do $14 \%$ do PIB. Xapón, Polonia e Portugal tamén rexistraron aumentos importantes no gasto público de pensións chegando 2003 a superar o 10\% do PIB nos tres países. Máis recentemente outros países como Portugal, España ou Grecia tamén acometeron reformas importantes.

As reformas levadas a cabo nos sistemas de pensións nos distintos países baseánse en diversos instrumentos. Dunha banda temos as reformas paramétricas (idade de xubilación, incentivos de prolongación da actividade, cálculo da pensión, actualización das bases de cotización, actualización da pensión e o factor de sustentabilidade) e por outra, as reformas estruturais (García et al., 2011).

\subsection{As reformas paramétricas}

As reformas paramétricas son relativamente recentes nos países europeos e a súa finalidade é por unha banda, fomentar a prolongación da vida laboral e por outra, tentar establecer unha relación entre as cotizacións e as prestacións. Estas medidas van encamiñadas a:

- Aumentar o período de cotización mínimo para ter dereito ao cobro do 100\% da pensión.

- Incrementar a idade de xubilación ordinaria e mínima.

- Modificar o índice de revalorización das pensións.

- Introducir mecanismos correctores do importe das pensións en función da evolución do PIB do país e da existencia dun déficit financeiro no sistema.

A meirande parte dos países europeos adoptaron reformas paramétricas xa que ao igual que España tamén soportan un importante déficit nos seus sistemas públicos de pensións. Na Táboa 2 podemos ver un resumo destas reformas levadas a cabo por distintos países europeos.

Unha das medidas máis utilizadas polos países é o retraso da idade de xubilación e os incentivos a percibir se se prolonga a actividade. Así, a idade de xubilación ampliouse na maioría dos países ata os 65 anos e nalgúns países aprobouse a súa progresiva ampliación ata os 67 anos e, o aumento da idade mínima de xubilación (véxase a Táboa 3 no Anexo).

Táboa 2.- Reformas paramétricas nos sistemas de pensións europeos 


\begin{tabular}{|c|c|c|c|c|c|c|}
\hline \multirow[b]{2}{*}{ PAIS } & \multirow[b]{2}{*}{$\begin{array}{l}\text { EDAD } \\
\text { JUBLACION }\end{array}$} & \multirow[b]{2}{*}{$\begin{array}{c}\text { NCENTINOS } \\
\text { PROLONGACION } \\
\text { ACTIVDAD }\end{array}$} & \multicolumn{2}{|c|}{ CALCULO PENSION } & \multirow[b]{2}{*}{$\begin{array}{l}\text { ACTUALIZACION } \\
\text { PENSION }\end{array}$} & \multirow[b]{2}{*}{$\begin{array}{l}\text { FACTOR } \\
\text { SOSTENIBLDDAD }\end{array}$} \\
\hline & & & MEDIDA & $\begin{array}{c}\text { ACTUALZACION } \\
\text { BASES }\end{array}$ & & \\
\hline Acruanis & $*$ & $*$ & & & & $\div$ \\
\hline Austrix & * & $*$ & $*$ & $*$ & & \\
\hline Bélgica & $*$ & $*$ & & $*$ & & \\
\hline Dinamxarca & $*$ & $*$ & & & & $*$ \\
\hline España & & $*$ & & & & \\
\hline Pmlandia & & $*$ & $*$ & $*$ & $*$ & $*$ \\
\hline Francia & & $\cdot$ & $*$ & $*$ & & $*$ \\
\hline \multicolumn{7}{|l|}{ Grocia } \\
\hline \multicolumn{7}{|l|}{ Molanda } \\
\hline Itanda & & $=$ & & & & \\
\hline Inalux & $\cdot$ & $*$ & & & $*$ & \\
\hline Luxermburyo & & & $*$ & & & \\
\hline Portugal & 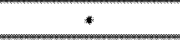 & $*$ & $*$ & $*$ & $*$ & $*$ \\
\hline Remo Unido & $\cdot$ & $*$ & & & $*$ & \\
\hline Suecra & & & - & & & \\
\hline
\end{tabular}

FONTE: OECD (2014)

En referencia ao cálculo do nivel da pensión, na actualidade existen países que teñen en conta toda a vida laboral para o cálculo da pensión, como Italia, Portugal, Grecia, Reino Unido e Suecia. Outros países só consideran os últimos anos da vida laboral dos individuos, por exemplo Francia considera os 25 últimos anos.

Outra das medidas baseánse nos mecanismos de actualización das contribucións e da revalorización das pensións. Uns países utilizan índices de crecemento salarial, malia que na actualidade a maioría dos países cambiaron este criterio pasando a utilizar o índice de prezos, que xeralmente ten un crecemento inferior ao do crecemento salarial. A título de exemplo (véxase a Táboa 4 no Anexo), Francia, Italia e Letonia utilizan o índice de prezos, Dinamarca, Holanda e Noruega utilizan os salarios e, o resto combina utiliza un sistema de índices mixto.

Todo este proceso reformista intensificouse nos últimos anos, establecéndose novos mecanismos para calcular a revalorización anual das pensións e introducindo o factor de sustentabilidade no sistema de pensións. O índice de revalorización fixará o crecemento anual das pensións en función dunha fórmula que se deriva da restrición orzamentaria do sistema. O factor de sustentabilidade é un mecanismo automático que vencella o importe inicial das pensións de xubilación á evolución da esperanza de vida.

Estas reformas levaronse a cabo en distintos países da nosa contorna nos últimos anos, introducíndose mecanismos automáticos de axuste nos sistemas de pensións. Como se aprecia na Táboa 4, o factor de sustentabilidade existe en diversos países, sendo a variable que xera o axuste automático (na pensión inicial, idade de xubilación ou outros parámetros do sistema) o incremento da esperanza de vida (Ramos, 2014:80).

Para o caso español, no ano 2011 apróbase a reforma do sistema de pensións máis importante das últimas décadas, co fin de acometer os problemas de viabilidade e sustentabilidade do sistema de pensións, a Lei 27/2011, do 1 de agosto, a cal aposta polo aforro social (López e Reig, 2014, 119-123). As principais medidas incluídas na reforma inclúen o retraso da idade de xubilación, o aumento do período de cotización necesario para recibir unha porcentaxe da base reguladora, e a ampliación do período de cómputo 
para o cálculo da pensión. Ademais, introdúcese no sistema a figura do factor de sustentabilidade e do índice de revalorización, co obxectivo de garantir a súa sustentabilidade e para manter a proporcionalidade entre as contribucións e as prestacións esperadas. A regulación normativa do factor de sustentabilidade e do índice de revalorización deriva das recomendacións incluídas no Informe do Comité de Expertos sobre o factor de sustentabilidade do sistema público de pensións (2013). O factor de sustentabilidade proposto no devandito informe procura que o sistema se sosteña por si só, minimizando os efectos do ciclo económico e atenuando os efectos sobre a pensión: en anos bos crece menos do que podería, e en anos malos cae menos do que debería. Cabe destacar que este Comité de Expertos considera necesario que os superávits de caixa que se produzan pasen íntegra e automaticamente ao Fondo de Reserva. Ademais, considera que o factor de sustentabilidade proposto é axeitado porque, entre outras razóns, permite seguir dotando con tales excedentes o Fondo de Reserva, converténdoo nun elemento útil para complementar as revalorizacións dos anos malos. Este novo obxectivo que se formula para o Fondo de Reserva aumenta a necesidade dunha modificación no seu mecanismo de aportacións, de forma que se estableza un criterio obxectivo de dotacións acorde coa súa finalidade (Anido et. al., 2014).

Diversas fontes coinciden en valorar positivamente os efectos da reforma española na sustentabilidade do sistema, aínda que as mesmas conclúen que sen considerar o factor de sustentabilidade a reforma resultaría insuficiente para garantir a súa futura viabilidade (Conde-Ruíz e González, 2012a; De la Fuente e Doménech, 2011; Domínguez et al., 2012; Meneu e Encinas, 2012; Ferruz e Alda, 2010; Boado e Lanot, 2012; Moral-Arce, 2013; Herce, 2013). Tamén coinciden en sinalar que, en troques, os importes das pensións serán rebaixados considerablemente.

Entre as medidas adoptadas para garantir a solvencia do sistema de pensións español destacamos a denominada "reforma silenciosa", que consiste en aumentar a base de cotización máxima nunha proporción maior á aplicada á pensión máxima. Esta medida podería ter un efecto de contención de gasto superior ao previsto pola reforma de 2011, diminuíndo considerablemente a pensión media (Conde-Ruíz e González, 2012b). Trátase así doutra medida orientada á redución do gasto en pensións.

Por outra banda, Zubiri (2012) afirma que o novo sistema de pensións é perfectamente sostible dende o lado do gasto e que os seus problemas financeiros futuros non se deben a aumentos desmesurados do gasto, senón a deficiencias notables dos ingresos. Daí que as medidas a adoptar deberían estar encamiñadas ao incremento dos ingresos do sistema.

Cunha reforma na que se obtiveran novos ingresos para o sistema (por exemplo, con impostos sobre a renda ou IVE), os excedentes que se xeraran poderían ser acumulados no Fondo de Reserva, o cal permitiría reducir o custo que se trasladou aos futuros xubilados, repartíndoo deste xeito entre xeracións e tipos de renda. En tal caso o Fondo de Reserva adquiriría maior relevancia, tanto polo seu maior peso no activo do sistema, como por converterse nun verdadeiro mecanismo de redistribución do gasto en pensións. Porén, baixo as condicións actuais, o Fondo de Reserva desempeña un escaso papel na sustentabilidade do sistema español de pensións, previsiblemente destinado ao seu esgotamento a medio prazo.

Conscientes da situación do Fondo de Reserva, algúns líderes políticos, están propoñendo posibles reformas. O candidato a presidente do Goberno do partido socialista, Pedro Sánchez avanzou que se consegueía formar goberno despois das eleccións do 26 de xuño de 2016 "impoñerá un «recargo de solidariedade» ás rendas e patrimonios máis altos para 
poder soster o sistema de pensións que arrastra un «déficit preocupante»" (La Voz de Galicia, 2016).

4.2. As reformas estruturais

Nalgúns países introducíronse nos seus sistemas de pensións reformas estruturais. Estas reformas supoñen o paso de mecanismos de reparto de prestación definida aos de contribución definida. Así, cabe destacar o sistema de contas nocionais introducido por Italia, Letonia, Noruega, Polonia ou por Suecia que teñen sistemas de contas nocionais de contribución definida, é dicir, son sistemas que funcionan baixo unha base actuarial: as contribucións dun traballador ao longo da súa vida laboral acumúlanse nunha conta ficticia (nocional) sobre a que se aplica un rendemento en función de variables demográficas, económicas ou as dúas, o cal determina o valor da pensión no momento da xubilación. O sistema italiano introducido no ano 1995 baséase en tres piares: un sistema de pensións público de reparto baseado no principio de contas nocionales, un sistema de capitalización complementario a través das empresas e un sistema privado voluntario. $\mathrm{O}$ sistema sueco difire do italiano, entre outras características, en que contén un mecanismo de axuste automático que se activa se a ratio de solvencia ou a ratio de balance do sistema é inferior á unidade, é dicir, se os activos por pensións son superiores aos pasivos por pensións.

Alemaña tamén introduciron reformas importantes no seu sistema público de pensións, conta cun sistema de puntos, o cal se basea en tres piares: (i) un plan de pensións público obrigatorio xestionado polo Goberno: inclúe arredor do $80 \%$ dos traballadores en activo 2 . O cálculo das pensións realízase cun sistema de puntos, é dicir, o traballador obtén «puntos pensionables» cuxo valor dependerá de que a contribución que se faga nun ano teña base nunha renda menor ou maior que a media dos ingresos de todos os contribuíntes. No momento da xubilación, acumúlanse os puntos de cada ano e a devandita suma multiplícase polo valor dun punto; (ii) un plan de pensións ocupacional privado: este foi introducido por Riester en 2001, e establece que o empresario está obrigado por lei a ofrecer ao traballador a posibilidade de converter parte do seu salario nunha futura prestación, a cal ten incentivos fiscais; e (iii) un plan de pensións privado de carácter voluntario.

5. Conclusións e implicacións

O progresivo avellentamento da poboación, o incremento da esperanza de vida e a mortaldade, ademais dunha contorna económica cambiante que se caracteriza por baixos rendementos, crecemento baixo e taxas de interese baixas, está provocando que os sistemas de pensións teñan que se enfrontar a problemas de sustentabilidade financeira. Isto levou a que a maioría dos países da OECD decidiran realizar reformas nos seus sistemas de pensións co obxectivo de garantir a sustentabilidade financeira dos mesmos. Se ben as reformas estanse levando a cabo dende os anos noventa, as reformas máis

2 Os funcionarios e a maioría dos autónomos non están baixo o esquema público, as súas pensións sufráganse directamente dos orzamentos públicos. Existen esquemas especiais para os agricultores e as profesións liberais (médicos, arquitectos ou avogados). 
activas déronse entre febreiro de 2012 e setembro de 2014. Basicamente as medidas a considerar para acometer as reformas virán ben por incremento dos ingresos (cotizacións), isto non parece moi acertado, pois suporía un maior custo para as empresas, ou en tentar reducir gastos (reducir o importe das pensións ou o seu tempo de pago). Ademais, os distintos líderes políticos xa manifestaron que se debe empezar a considerar a posibilidade de analizar outras vías de financiamento adicionais.

O estudo sobre o papel do Fondo de Reserva na sustentabilidade do sistema de pensións permitiunos identificar oportunidades de mellora e poder formular aos organismos oficiais a posibilidade de ter en conta unha serie de recomendacións:

Ampliar e aumentar as fontes de financiamento do sistema, a través dun axeitado esquema impositivo, destinando aos Fondos de Reserva os excedentes que se poidan xerar. Poderiase considerar, como xa se está formulando, a posibilidade de obter novos ingresos para o sistema mediante impostos, o cal permitiría reducir o custo que se trasladou aos futuros xubilados, repartíndoo deste xeito entre xeracións e tipos de renda.

Regulamentar un criterio obxectivo, no canto de que sexa unha decisión política como no caso de España, para a determinación do importe das aportacións ao Fondo de Reserva, co fin de que sexa posible cumprir co obxectivo que se estableza para o mesmo.

O Goberno debería remitir ao Congreso o informe sobre a avaliación do cumprimiento das recomendacións aprobadas en 2011, froito da revisión do Pacto de Toledo, co fin de que a Comisión Parlamentaria do mesmo puidese debater e renovar as devanditas recomendacións, abrindo un proceso de negociación entre os interlocutores sociais e 0 Goberno, co fin de reforzar os ingresos do sistema.

Adoptar unha xestión activa dos distintos riscos que enfrontan os investimentos no que se atopa materializados o Fondo de Reserva. Estudar a posibilidade de diversificar 0 investimento do Fondo, volvendo ao investimento en renda fixa en outros países ou incluso a posibilidade de investir unha parte do Fondo en renda variable.

Aumentar a transparencia do rexime de pensións públicas, tal como se esixe ao sector privado, proporcionando información periódica sobre a situación do sistema. O Goberno debe informar e concienciar á poboación sobre o estado actual do Fondo de Reserva e sobre o problema da sustentabilidade no futuro das pensións públicas.

Dado que a reforma das pensións públicas conducirá previsiblemente á redución das mesmas, o Gobierno debería estudar a posibilidade de instaurar un sistema obrigatorio de aportacións a sistemas privados, como complemento á pensión pública, co fin de garantir que os cidadáns teñan uns ingresos razoables á hora de xubilarse, na liña do realizado noutros países como Suecia ou Italia.

Por último, sería interesante que o Goberno estudase a posibilidade de introducir incentivos fiscais tales como: dedución na cota do Imposto de Sociedades para as aportacións empresariais, incentivar a promoción de planes sectoriais ou aumentar os límites financeiros e fiscais de dedución do IRPF para as aportacións a plans no ámbito empresarial.

A instauración destas recomendacións podería converter o Fondo de Reserva nun elemento relevante na solvencia do sistema de pensións, contribuíndo á súa sustentabilidade e aumentando a equidade entre as xeracións de pensionistas.

\section{Bibliografía}


ANIDO, M.; MAREQUE, M.; LÓPEZ-CORRALES, F. (2014): “El Fondo de Reserva de la Seguridad Social y su papel en la sostenibilidad del sistema de pensiones", CIRIEC-España, Revista de economía pública, social y cooperativa, 80, pp.187-218.

BAREA, J.; GONZÁLEZ-PÁRAMO, J.M.; VELARDE, J. (1997): Pensiones y prestaciones por desempleo, Bilbao, $2^{\mathrm{a}}$ edición, Fundación BBVA.

BBVA (2014): "Comparativa de la edad de jubilación: España y resto de Europa”, Instituto BBVA de pensiones. En: https:// www.jubilaciondefuturo.es/ es/ blog/ comparativa-de-la-edad-dejubilacion-espana-y-resto-de-europa.html

BOADO, M.; LANOT, G. (2012): "Impacto redistributivo y solvencia ante reformas en el sistema de pensiones español: una aproximación a partir de la Muestra Continua de Vidas Laborales", Ministerio de Empleo y Seguridad Social, www.seg-social.es.

COMISIÓN EUROPEA (2010): "Libro verde, en pos de unos sistemas de pensiones europeos adecuados, sostenibles y seguros", SEC (2010) 830, Disponible en: http:/ / ec.europa.eu/ social/ main.jsp?langId=enycatId=752ynews Id=839yfurthernews=yes

CONDE-RUIZ, J.I.; GONZÁLEZ, C.I. (2012a): "Reforma de pensiones 2011 en España: una primera valoración", Fundación de Estudios de Economía Aplicada, Colección Estudios Económicos, 012012, pp. 1-37.

CONDE-RUIZ, J.I.; GONZÁLEZ, C.I. (2012b): "La Reforma silenciosa": los efectos de los límites máximos y mínimos (de cotización y pensiones) sobre la sostenibilidad del sistema, Ministerio de Empleo y Seguridad Social", www.seg-social.es.

CONGRESO DE LOS DIPUTADOS (1995). "Pacto de Toledo". Boletín Oficial de las Cortes Generales de 12 de abril de 1995, No. 134.

DE LA FUENTE, A.; DOMÉNECH, R. (2011): "El impacto sobre el gasto de las reforma de las pensiones: una primera estimación", Fundación de Estudios de Economía Aplicada, Colección Estudios Económicos, 03-2011.

DOMÍNGUEZ, I.; DEVESA, M.; ROSADO, B. (2012): "La Muestra Continua de Vidas Laborales y su potencial para analizar la solvencia del sistema de pensiones desde la perspectiva del empleo", Ministerio de Empleo y Seguridad Social, www.seg-social.es.

EUROPEAN COMMISSION (2012): “The 2012 Ageing Report”, European Economy, 2/ 2012.

FERRUZ, L.; ALDA, M. (2010): "The reform of some European public pension systems: Spain, Italy and Sweden: A breakthrough?", Pensions, 15 (4), pp. 297-304.

FONDS DE RESERVE POUR LES RETRATTES (2011): 2011 Annual report, Paris.

GARCÍA, D.; GORDO, E.; MANRIQUE, M. (2011): "Reformas de los sistemas de pensiones en algunos países de la UEM", Boletín económico del Banco de España, julio-agosto.

HERCE, J.A. (2013): “La reforma de las pensiones en España”, Cuadernos de Información Económica, 35, p. 33-40.

HERCE, J.A.; PÉREZ-DÍAZ, V. (1995): "La reforma del sistema público de pensiones en España", Colección Estudios Económicos, 4 (Diciembre), Servicio de Estudios de La Caixa, Barcelona.

HERCE, J.A.; S. SOSVILLA, S.; CASTILLO, S.; DUCE, R. (1996): "El futuro de las pensiones en España: hacia un sistema mixto", Colección Estudios Económicos, 8 (Diciembre), Servicio de Estudios de La Caixa, Barcelona.

ISSA (2004): "Directivas para la inversión de los fondos de la seguridad social", Asociación Internacional de la Seguridad Social, Ginebra.

LÓPEZ-GANDÍA, J. (2008): "El Fondo de Reserva de la Seguridad Social“, Temas laborales: Revista andaluza de trabajo y bienestar social, 94, pp. 179-202.

LÓPEZ-SANGUOS, D.; DE LAS HERAS, A. (2012). “Un colchón para la Seguridad Social: el Fondo de Reserva”, CEF.-Trabajo y Seguridad Social, 346, pp.149-166. 
LÓPEZ, J.; REIG, A. (2014): “El sistema público de pensiones”, Revista Galega de Economía, 23 (1), pp. 115-136.

MENEU, R.; ENCINAS, B. (2012): “Valoración de la reforma del sistema de pensiones español 2011 desde la óptica de la viabilidad financiero-actuarial. Un análisis a través de MCVL", Ministerio de Empleo y Seguridad Social, www.seg-social.es.

MINISTERIO DE TRABAJO Y SEGURIDAD SOCIAL (1995): La Seguridad Social en el umbral del siglo XXI. Estudio económico actuarial, Madrid.

MEYSS (2008): Fondo de Reserva de la Seguridad Social. Evolución, actuaciones del año 2007 y situación a 31-12-2007, Informe a las Cortes Generales.

MEYSS (2012): Fondo de Reserva de la Seguridad Social. Informe a las Cortes Generales. Evolución, actuaciones del año 2011 y situación a 31 de diciembre de 2011, Informe a las Cortes Generales.

MEYSS (2013): Fondo de Reserva de la Seguridad Social. Informe a las Cortes Generales. Evolución, actuaciones del año 2012 y situación a 31 de diciembre de 2012, Informe a las Cortes Generales.

MEYSS (2014): Fondo de Reserva de la Seguridad Social. Informe a las Cortes Generales. Evolución, actuaciones del año 2014 y situación a 31 de diciembre de 2014, Informe a las Cortes Generales.

MORAL-ARCE, I. (2013): "Aplicación de Factores de Sostenibilidad en el sistema de pensiones español: previsiones para el periodo 2012-2050", Instituto de Estudios Fiscales, P.T. no 4/ 2013.

OCDE/ OECD(2012): Pensions Outlook 2012, OECD Publishing.

OECD/OECD (2014): Annual Survey of Large Pension Funds and Public Pension Reserve Funds 2014. Report on pension funds' Long-Term Investments. Disponible en: http:/ / www.oecd.org/ daf/ fin/ private-pensions/ survey-large-pension-funds.htm

PIÑERA J.; WEINSTEIN, A. (1996): “Una propuesta de reforma del sistema de pensiones”, Círculo de Empresarios, Madrid.

RAMOS, R. (2014): "El factor de revalorización y de sostenibilidad del sistema de pensiones español", Boletín Económico del Banco de España, julio-agosto.

UGT-CEC (2010): "Situación actual del sistema de Seguridad Social y del Fondo de Reserva", febrero de 2010.

ZUBIRI, I. (2003). El futuro del sistema de pensiones, Madrid, Instituto de Estudios Fiscales.

ZUBIRI, I. (2012): "Reforma y sostenibilidad del sistema de pensiones: una valoración crítica", Economía Española y Protección Social, IV, pp. 59-105.

ZUBIRI, I. (2013): "Por Ignacio Zubiri: Reforma injusta y engañosa". Disponible en: http:/ / alternativaseconomicas.coop/ posts/ por-ignacio-zubiri-reforma-injusta-yenganosa/ page/ 2.

\section{Legislación y Notas de Prensa.}

EL ECONOMISTA (2012): "Barea advierte de que el gobierno acude "muy pronto" al Fondo de Reserva ",". http:// www.eleconomista.es/ economia/ noticias/4294441/ 10/12/ Barea-adviertede-que-el-gobierno-acude-muy-pronto-al-fondo-de-reserva-de-la-seguridad-social.html

GOBIERNO DE ESPAÑA (2013): “Empleo presenta a la Comisión Delegada de Asuntos Económicos el informe sobre la utilización del Fondo de Reserva de la Seguridad Social en 2012". En: http:/ / www.lamoncloa.gob.es/ ServiciosdePrensa/ NotasPrensa/

MinisterioEmpleoySeguridadSocial/ 2013/ 180113FondoReservaSS.htm

LA VOZ DE GALICIA (2016): Pedro Sánchez propone un «recargo de solidaridad» para pagar las pensiones. http:// www.lavozdegalicia.es/ noticia/ espana/ 2016/ 05/ 23/ pedro-sanchez-impondrarecargo-solidaridad-pagar-pensiones/ 00031463989856212792189.htm

LEY 27/2011, de 1 de agosto, sobre actualización, adecuación y modernización del sistema de Seguridad Social (BOE, nํ 184, de 2 de agosto de 2011). 
MINISTERIO DE EMPLEO Y SEGURIDAD SOCIAL (MEYSS) (2015): "Las Seguridad Social dispone 7750 millones de euros del Fondo de Reserva". Disponible en: http:/ / prensa.empleo.gob.es/ WebPrensa/ noticias/ seguridadsocial/ detalle/ 2721.

MINISTERIO DE LA PRESIDENCIA (2010): Consejo de Ministros. Referencia 26 de febrero de 2010, pp. 18.

MINISTERIO DE LA PRESIDENCIA (2012): Consejo de Ministros. Referencia 27 de septiembre de 2012, pp. 21.

REAL DECRETO 337/2004, de 27 de febrero, por el que se desarrolla la Ley 28/2003, de 29 de septiembre, reguladora del Fondo de Reserva de la Seguridad Social (BOE no 59 de 9 de marzo de 2004).

REAL DECRETO LEY 28/2012, de 30 de noviembre, de medidas de consolidación y garantía del sistema de la Seguridad Social (BOE no 289 de 1 de diciembre de 2012).

Anexo on line: https:// ideas.repec.org/ s/ sdo/ regaec.html

Web: http:/ / www.usc.es/ econo/ RGE/ benvidag.htm 